\title{
A. A. Аствацатуров
}

\section{АНДРЕЙ ИВАНОВ И ГЕНРИ МИЛЛЕР: ОПЫТ СОПОСТАВИТЕЛЬНОГО АНАЛИЗА}

Санкт-Петербургский государственный университет, Российская Федерация, 199034, Санкт-Петербург, Университетская наб., 7-9

В статье проводится сравнительный анализ текстов русского писателя Андрея Иванова (р. 1971) и американского культового автора Генри Миллера (1891-1980). В своей «скандинавской трилогии», которая принадлежит к серьезным явлениям современной русской прозы, Андрей Иванов развивает специфическую традицию американской литературы, связанную с текстами Генри Миллера и восходящую к Г.Д. Торо и Уолту Уитмену. В статье делается попытка проследить трансформацию этой традиции в прозе Андрея Иванова. Отмечается некоторое сходство в биографиях обоих писателей, их статус иностранцев, «чужаков» в культуре, которой они принадлежат. Авторы связаны общим религиозным поиском, представлением о бессмысленности мира и наличии во всех его проявлениях скрытой энергии. Но в то время как Генри Миллер видит в ней источник удовольствия и пытается заставить своего персонажа с ней воссоединиться, Андрей Иванов, ощущая ее присутствие в мире, ужасается. Библиогр. 25 назв.

Ключевые слова: Генри Миллер, Андрей Иванов, техника каталога, анекдоты, модернизм.

\section{ANDREI IVANOV AND HENRY MILLER: COMPARATIVE ANALYSIS}

\section{A. A. Astvatsaturov}

Saint Petersburg State University, 7-9, Universitetskaya nab., St. Petersburg, 199034, Russian Federation

The paper offers a comparative study of two figures in Russian and American literature: Andrey Ivanov (b. 1971) and Henry Miller (1891-1980). One of the modern Russian writers, Andrey Ivanov deliberately focuses and develops in his "Scandinavian trilogy" a certain tradition of American Literature which is represented in the writings of Henry Miller and historically involves such figures as H. D. Thoreau and W. Whitman. The paper attempts to trace the transformation of this tradition in Andrey Ivanov's novels. It emphasizes some similarities in their biographies, their specific alien status in the countries where they live. Both shared a common religious search, the notion of the irrationality of the world run by the latent energy hidden in its diverse manifestations. However the moral evaluation toward this energy is different. While Henry Miller is positive and rejoices the reunion of his narrator with it, Andrey Ivanov seems to be negative. Refs 25.

Keywords: Henry Miller, Andrey Ivanov, catalogue technique, anecdotes, modernism.

В настоящей статье мы попытаемся показать специфику трансформации в текстах современного русского писателя Андрея Иванова одной из многочисленных традиций американской литературы, связанной с фигурой Генри Миллера. Творчество Генри Миллера (1891-1980), культового американского писателя, на сегодняшний день, как справедливо отмечают его исследователи [Decker, p. 148], изучено крайне слабо. Относительно его знаменитых книг «Тропик Рака», «Черная Весна», «Тропик Козерога», составивших так называемую «парижскую трилогию», у филологов нет научного консенсуса: они расходятся в оценках и трактовках. В свою очередь, тексты Андрея Иванова (р. 1971), лауреата и финалиста нескольких престижных литературных премий, автора романов «Путешествие Ханумана на Лолланд», «Горсть праха», «Харбинские мотыльки», «Бизар», хотя и широко рецензировались в России авторитетными критиками [Левченко; Бавильский; Гурьев; Кучерская;

() Санкт-Петербургский государственный университет, 2016 
Степанов], но лишь изредка подвергались филологическому анализу [Белобровцева; Аствацатуров, 2013; Аствацатуров, 2014]. Впрочем, рецензенты уже успели обратить внимание на связь его текстов с некоторыми российскими [Левченко] и западными маргинальными литературными традициями [Подлубнова], в частности с литературой «битников» [Степанов]. Это, разумеется, справедливо, однако схожесть текстов представителей бит-поколения (Джека Керуака, Уильяма Берроуза) и Андрея Иванова, помимо фабульного материала и наличия антисоциальных персонажей, объясняется тем, что у них было несколько общих литературных учителей, среди которых такой масштабный автор, как Генри Миллер.

И Генри Миллер, и Андрей Иванов автобиографичны. Оба в своих текстах тяготеют к внешней бесструктурности, фрагментарности. И тот и другой ориентируются на традицию плутовского романа, выводя антигероев-авантюристов [Подлубнова], пикаро [Decker, p. 60], отвергающих этические императивы. Оба вместо последовательного нарратива предлагают серию анекдотов. И наконец, оба используют похожий арсенал художественных приемов.

Мы попытаемся сопоставить ряд ключевых аспектов в творчестве двух авторов, касающихся главным образом их мировидения. Здесь в первую очередь нас интересуют тексты «парижской трилогии» Миллера и романы «скандинавской трилогии» Андрея Иванова, прежде всего «Бизар».

Можно отметить не только схожесть сюжетных линий, мотивов, идеологических доминант их текстов, ориентированных на одни и те же жанровые традиции, но и некоторые поразительные совпадения в биографиях. Для обоих, Миллера (немца по происхождению) и Андрея Иванова (русского), страна, в которой они родились (США и Эстония), была во многом чужой. Оба в какой-то момент вынуждены были эмигрировать (Миллер - во Францию, Андрей Иванов - в Данию), оба бродяжничали и вели образ жизни маргиналов. Существенно, что в обоих случаях мы имеем дело с обнаруживающей себя культурной инаковостью, внесистемностью, вненаходимостью. Есть, однако, принципиальное различие, которым определяется серьезное расхождение в мировоззренческих и философских позициях обоих авторов: все поступки Миллера совершаются добровольно и диктуются внутренними поисками, Андрей Иванов всегда действует вынужденно [Аствацатуров 2013, с. 146].

Это отношение к человеку вызывает и эстетические расхождения обоих авторов, кажущихся столь близкими. Напомним, что Генри Миллер вырабатывает свою индивидуальную манеру письма лишь в Европе после того, как под влиянием своих парижских друзей он знакомится с текстами европейских модернистов: Гамсуна, Лоуренса, Джойса, Элиота, Пруста. Он, как верный ученик, усваивает их открытия, но тем не менее страх влияния, о котором писал Гарольд Блум [Bloom, c. 5-18], убежденность в собственном величии, интерес к своему меняющемуся «я» заставляют его, как отмечают исследователи [Ibargüen, p. 65-66; Rosenquist, p. 111137]), отвергнуть холодный профессионализм высоких модернистов, их призывы к мастерской отточенности, завершенности текста, обращенного к себе. Используя приемы Гамсуна, Пруста, Джойса, Миллер обнаруживает несколько иное отношение к литературной работе, к творчеству, то, которое разделяли кумиры его молодости: Р. У.Эмерсон, Генри Торо и Уолт Уитмен. Цель творчества, в его понимании, не создание завершенного текста, а развитие «я». Творчество интересно ему по- 
стольку, поскольку оно способствует изменению личности творящего, открытию новых ценностей. Соответственно представление о литературе как о профессиональном ремесле Миллером отвергается. Он критикует представителей литературного истеблишмента, писателей-профессионалов [Миллер, 2015, с. 295], модернистов [Миллер, 2001], замкнувшихся в герметичном мире слов, и вполне осознанно и демонстративно позиционирует себя по отношению к ним как маргинал и дилетант.

Андрей Иванов, судя по его многочисленным высказываниям на эту тему, возвращается на неоклассицистские позиции высокого модернизма [Иванов, 2010] и в духе Т.С.Элиота, защищавшего идею «имперсональной поэзии» [Элиот, c. 157-165], в интервью и на встречах с читателями говорит о самоустранении автора в процессе сочинения. В отличие от Миллера, в собственном творчестве он сам себе как человек неинтересен. Он ставит своей целью подчинение личности процессу генерирования текста. Иванов усваивает приемы автора «Тропика Рака», но включает их в иную парадигму, парадигму высокого модернизма, которую Миллер отвергал. Тем самым русский писатель возвращает Миллера, авангардно шагнувшего за грань литературы, обратно - в ее пределы.

Эти расхождения достаточно любопытны, особенно если учесть ряд общих мировоззренческих позиций двух писателей. И Генри Миллер, и Андрей Иванов одинаково отрицают власть рассудка (интеллекта, идеалов, этических принципов), который является репрессивным механизмом, организующим и систематизирующим реальность. В романах «парижской трилогии» Миллер атакует рассудок, возвысившийся над жизнью. Его повествователь бросает вызов иудео-христианской идее Бога, возведенного в Абсолют [Миллер, 2000, с.22], идеалам, морали, обезличенному знанию. Андрей Иванов противопоставляет изменчивой и спонтанной жизни неподвижный рассудок, формульное знание, которое реализуется в жестком дисциплинарном пространстве. Это пространство порядка в романе «Путешествие Ханумана на Лолланд» представлено в образах широких автобанов и аккуратно проложенных железных дорог, по которым в Дании предписано перемещаться и которых персонажи романа, Хануман и Юдж, стараются избегать. Свобода в Европе оказывается мнимой. И Дания, таким образом, изображается Ивановым как территория строгого надзора [Иванов, 2009, с. 7]. Роман обнажает знаменитую гамлетовскую метафору «Дания - тюрьма». Это ощущение в «Бизаре» поначалу смягчается, но уже в конце второй части романа возвращается предостережениями Ханумана: «Ты не представляешь, что сейчас творится в мире беженцев Дании! Юдж, это просто бизар! <..> кто получил отказ, того - в Сундхольм, в обезьянник, в закрытый кемп, чтоб не сбежал никуда, не лег на дно, не пустился воровать, не вышел на большую дорогу. Выпускают по пропускам. Всюду камеры слежения. Обязан выходить на перекличку и отмечаться» [Иванов, 2014, с. 194].

В то же время надзирающий рассудок никогда окончательно не может подчинить себе изменчивую, становящуюся реальность. Она отталкивает предписываемые ей смыслы, уворачивается от постижения, демонстрирует независимость от моральных, этических принципов и полное равнодушие к человеческим усилиям. Генри Миллер и Андрей Иванов в своих текстах придерживаются этой идеи, и оба стремятся ее проиллюстрировать одним и тем же примером - картиной одинокого человека, созерцающего море, бескрайнюю водяную массу. В «Колоссе Ма- 
руссийском» Миллер находится на палубе парохода и наблюдает закат: «Это был один из тех библейских закатов, где человеку нет места. Природа просто раскрывает окровавленную, ненасытную пасть и заглатывает все, что есть вокруг. Закон, порядок, мораль, справедливость, мудрость, любое абстрактное понятие кажутся жестокой шуткой, что сыграли с беспомощным миром идиотов. По мне, закат на море - жуткое зрелище: отталкивающее, кровавое, бездушное. Земля может быть бессердечной, но море - безжалостно. Спастись абсолютно негде - в царстве четырех стихий, и стихий коварных» [Миллер, 2001, с. 85]. Сцена оказывается символической: Миллер говорит о спасении в религиозном смысле, о кажущейся невозможности духовно спастись и примириться с миром и Богом. Кровавый закат, напоминающий раскрытую пасть древнего чудовища, видится ему апокалиптическим, обнуляющим человеческие усилия и человеческий мир. Море равнодушно к человеку и неизбежно сводит на нет все его ценности, представления и смыслы.

В романе Андрея Иванова картина моря подталкивает персонажа к похожим экзистенциалистским размышлениям: «Это же самая грандиозная свалка! Море! Посмотри на него! Это же омерзительно! Отвратительная безличная масса воды, вот и всё! < ..> Морю безразлично, если ты в него плюнешь. Ему даже по кайфу будет умножиться на каплю. Ты не можешь его пнуть ногой или дать тычка. Понятно, что камню, о который ты споткнешься, нет дела, он и не почувствует боли, если ты пнешь его в отместку. Но море ты даже ударить не сможешь! <...> Оно будет издеваться, кривить тебе рожи, смеяться в лицо, а ты ничего не можешь ему сделать, ничего!» [Иванов, 2014, с.57-58]. Персонаж Иванова в этой сцене, как мы видим, также утверждает полную несвязанность, изначальную разобщенность человека и мира. Морю, реальности нет дела до человеческих расчетов, ценностей, планов на жизнь. Упоминание Хануманом камня отсылает читателя к хрестоматийному эпизоду в романе Ж.-П.Сартра «Тошнота», где камень, поднятый с земли, вызывает тошноту и омерзение своей иррациональностью, бессмысленностью, равнодушием к человеческим ценностям. Море в представлении героя оказывается еще хуже, экзистенциально тошнотворнее, нежели камень.

Абсурдность становится неотменимым свойством той реальности, которую изображают Генри Миллер и Андрей Иванов. Она всегда - область случайного, единичного, отменяющего человеческие обобщения. Анекдотичны и нелепы уже сами истории, которые происходят с персонажами Миллера и Иванова, и не случайно оба писателя постоянно обращаются к жанру анекдота и фактически составляют из анекдотов свои нарративы [Decker, p. 9]. При этом Андрей Иванов оказывается менее радикальным, нежели Миллер. В отличие от автора «Тропиков», он не строит свой роман как хаотичное нагромождение анекдотов, а организует эпизоды в логической и временной последовательности, избирая осторожную стратегию Кнута Гамсуна («Голод»).

Это выглядит парадоксальным, если учесть, что он более открыто и форсированно, чем Миллер, заявляет о хаотичности и бессмысленности жизни. Уже в самом начале романа «Бизар» Юдж и Хануман заводят об этом разговор: «Это все равно бессмысленно, - добавил я. - Ворочайся, не ворочайся - все бессмысленно!

- Да, да, все бессмысленно, - пробурчал Хануман, взбивая подушки» [Иванов, 2014, c.5]. Предметная реальность и природа выглядят у Иванова бессмысленны- 
ми, духовно пустыми, безучастными к человеку: «Так и было: в природе чувствовались скудость и безразличие» [Иванов, 2014, с. 56].

Мир создан не в соответствии с человеческой логикой, и потому все попытки навязать ему смыслы, отстоять ценности, добиться целей обречены на провал. Человека всегда подстерегает неудача. Миллер в своих романах неизменно издевается над американской мечтой [Миллер, 2000, с. 49.], но в то же время осуждает доктрины, стремившиеся исправить мир [Миллер, 2015, с. 92].

В «Бизаре» все усилия, предпринятые персонажами, оказываются напрасными. Даже тщательно продуманные авантюры и махинации заканчиваются неудачно. Герои либо теряют деньги, либо попадают за решетку. Уклоняющийся от соблюдения этических императивов мир несправедлив к человеку, но персонажи Андрея Иванова, подобно персонажам Миллера, принимают это и отказываются от желания что-либо менять. «Мир спасать! А кому это нужно?» [Иванов, 2014, с. 89] - задается вопросом Хануман.

Демонстрируя тщетность всех рациональных попыток усмирить, познать, подчинить мир, персонажи Генри Миллера и Андрея Иванова констатируют внечеловеческий характер замысла вселенной. Они преодолевают антропоцентрическое видение мира (или хотя бы гуманистическое) и представляют реальность без человека, вне человека [Миллер, 2000, с. 253-254; Иванов, 2014, с. 25].

Представление о непостижимости мира, о внечеловеческом замысле заставляет центральных персонажей в романах Миллера и Иванова прийти к выводу о том, что в основе сущего присутствует некая сила, воля, пронизывающая человека и все вещи, отчего мир всегда видится изменчивым, становящимся. И Миллер, и Иванов прибегают к общему способу репрезентации этой бестелесной энергии, раскрывая ее техникой каталога, чередования вещей и действий. Каталоги часто возникают в урбанистических зарисовках романа «Тропик Рака»: «Сен-Сюльпис! Толстые колокольни, кричащие афиши на дверях, мерцающие алтарные свечи... Площадь, которую так любил Анатоль Франс, - бормотание, доносящееся из-за алтаря, плеск фонтана, воркующие голуби, хлебные крошки, исчезающие словно по волшебству, и глухое урчанье в пустых кишках» [Миллер, 2000а, с. 39].

Андрей Иванов в «Бизаре» каталогизирует предметы: «У них были семьи, по нескольку семей на каждого, дети, кредиты, квартиры, машины, работы...» [Иванов, 2014, с.20]. Однако еще чаще он вводит в текст перечни действий: «Растить траву, пропалывать ивовый сад, бродить коридорами замка, выплескивать воду из окон, бесконечно латать крышу, переставлять посудины, бросать уголь в топку, выгребать шлак, выплескивать воду» [Иванов, 2014, с. 116]. И у Миллера, и у Иванова каталоги, перечни предметов и действий ставят целью ослабить материальное и обнаружить спрятанную в дискретных формах жизни волну, движение, энергию, которая их порождает [Coffman, p.61-71].

Эта сила и есть подлинное начало вселенной и всех ее проявлений. Проблема здесь лишь в том, что повествователи у Миллера и у Иванова дают этой силе разную оценку. Миллер восторгается ею как источником удовольствия и вселенской мудрости, в то время как Юдж Сидоров ужасается и воспринимает ее как злую волю, тупую биологическую силу, заражающую человека грехом и разлагающую его: «Иногда самые незатейливые предметы внушали ужас: за ними маячила судьба, рок, предопределение и что-то вроде того» [Иванов, 2014, с. 120]. Обнаружение 
воли у Генри Миллера и у Андрея Иванова есть ключ к разгадке замысла. Но познать ее и окончательно проникнуть в замысел можно, лишь совпав с ее движением, открыв ее в себе самом. Персонажи Миллера и Иванова в какой-то момент оказываются подхваченными общим движением жизни и деиндивидуализируются [Миллер, 2000а, с. 287; [Иванов, 2014, с. 21, 25].

Деиндивидуализация, обнуление, утрата персонажем свойств, игнорирование императивов привычной этики имеют в романах Генри Миллера и Андрея Иванова религиозный смысл. В данном контексте принципиален общий литературный источник, «Божественная комедия» Данте. Миллер-рассказчик вспоминает Данте и цитирует его главным образом в романе «Тропик Козерога». Герой совершает путешествие в сферу предсуществования жизни, к бессознательному, к воле, к изначальности, символом которой становится его жена Мона: «...я видел слово “Надежда”, насаженное на вертел, - вот оно обжаривается, истекая жиром, непрерывно вращаясь в глазнице третьего глаза. Я слышал невнятное бормотание ее грез на давно забытых языках, сдавленные вопли, гулким эхом отдающиеся в мельчайших трещинах, стоны, хрипы, вздохи облегчения, свист рассекающих воздух плетей» [Миллер, 2000, с. 301]. Миллер демонизирует Мону, уподобляя свои взаимоотношения с ней дантевскому погружению в Ад, в отчаянье, в область, где теряется почти все субъективное, этическое и в том числе надежда на спасение.

В ключевых романах Андрея Иванова («Путешествие Ханумана на Лолланд», «Харбинские мотыльки», «Бизар») герои-рассказчики (Юдж Сидоров, Борис Ребров) по мере развития сюжета погружается в личный Ад, в кошмар первоначала, лишаясь этики и субъективных свойств. Они совершают движение от одной безысходности к другой, всякий раз почти достигая предела отчаяния. Но, достигнув его, они неизменно делают шаг в новый мир, который, возможно, станет их Чистилищем. Юдж в конце романа «Бизар» бежит из датской тюрьмы на свободу, а Ребров - из оккупированной Эстонии в свободную Швецию.

Различия в отношении к телу, к его потребностям, разделяющие Генри Миллера и Андрея Иванова, связаны с представлением авторов о взаимоотношении субъекта и мировой воли. Миллер избирает путь ницшеанского героя, дионисийского танцора, «гения», «гиперборея», сверхчеловека. Актуализируя в себе мировую волю, он обретает способность ею управлять и, меняя мир, открывать новые ценности. В свою очередь, персонаж Андрея Иванова не в состоянии направить движение воли и пассивно следует ее течению: «Если жизнь неумолимо жестока, почему я не могу быть жестоким тоже?» [Иванов, 2014, с. 25] - задается вопросом Юдж.

Сопоставительный анализ двух литературных фигур, выявление сходств и различий позволяют нам утверждать, что важная линия американской литературы, связанная с фигурой Миллера и восходящая к Г. Торо и У. Уитмену, неожиданно обнаруживает себя в современной русской прозе, хотя серьезным образом трансформируется, замыкаясь в границах литературы и утрачивая присущий ей оптимизм.

\section{Литература}

Аствацатуров А.А. Русский Керуак в Эстонии: проза Андрея Иванова // Труды международной научной конференции «Культура русского зарубежья 1990-2010» / под ред. А. Л.Хлобыстина. СПб.: Фак. свободных искусств и наук СПбГУ, 2013. С. 145-149.

Аствацатуров А.А. Современная литература русского зарубежья о России: писатель Андрей Иванов // Динамика языковых и культурных процессов в современной России: матер. конф. 
«IV Конгресс “РОПРЯЛ”, проходящий в рамках I Педагогического форума “Русский язык в современной школе” (Сочи, 1-2 ноября 2014 г.). Т. 2. СПб.: РОПРЯЛ, 2014. С. 131-137.

Бавильский Д. Екатеринентальский квартет // Частный корреспондент. 2014. 24 янв. URL: http:// www.chaskor.ru/article/ekaterinentalskij_kvartet_32845 (дата обращения: 18.04.2015).

Белобровцева И. Писательство как постоянная стадия зеркала. Андрей Иванов // Вопросы литературы. 2014. № 2. С. 254-271.

Гурьев М. Андрей Иванов. Харбинские мотыльки // DELFI. 2014. 15 aпр. URL: http://www.delfi.lv/ showtime/news/culturepark/books/andrej-ivanov-harbinskie-motylki.d?id=44402845 (дата обращения: 18.04.2015).

Делез Ж. Критика и клиника. СПб.: Machina, 2002. 240 c.

Иванов А. Путешествие Ханумана на Лолланд. Таллин: Авенариус, 2009. 332 с.

Иванов А. Мне не нужны ключи от квартиры в Париже // Новые облака. 2010. № 1-2. URL: http://tvz. org.ee/index.php?page $=430$ (дата обращения: 20.04.2015).

Иванов А. Бизар. М.: РИПОЛ классик, 2014. 352 с.

Кучерская М. Лауреатом премии «НОС» стал писатель из Таллина Андрей Иванов // Ведомости. 27.01.2014. URL: http://www.vedomosti.ru/lifestyle/articles/2014/01/27/dikovinka (дата обращения: 18.04. 2015).

Левченко Я. Читать // Однако. URL: http://www.odnako.org/almanac/material/chitat-1 (дата обращения: 13.04.2015).

Миллер Г. Тропик Козерога. СПб.: Азбука, 2000. 544 с.

Миллер Г. Тропик Рака. СПб.: Азбука, 2000а. 448 с.

Миллер Г. Вселенная смерти // Аэрокондиционированный кошмар: эссе, рассказы. М.: Б. С. Г.-ПРЕСС; Пушкин. б-ка, 2001. С. 343-368.

Миллер Г. Колосс Маруссийский. СПб.: Азбука-классика, 2001а. 320 с.

Миллер Г. Замри, как колибри: повести, рассказы, статьи. СПб.: Азбука, Азбука-Аттикус, 2015. 320 с.

Подлубнова Ю. Будни «азулянта» // Урал. 2010. № 12. URL: http://uraljournal.ru/work-2010-12-175 (дата обращения: 14.04.2015).

Степанов А. Д. Андрей Иванов. Путешествие Ханумана на Лолланд // Прочтение. 2010. 28 июля. URL: http://prochtenie.ru/reviews/24974 (дата обращения: 18.04.2015).

Элиот Т. С. Назначение поэзии. Киев: Airland, 1996. 352 с.

Bloom H. The Anxiety of Influence. A Theory of Poetry. 2nd ed. New York; Oxford: Oxford Univ. Press, 1997.

Coffman S. K. "Crossing Brooklin Ferry": a note on the Catalogue Technique in Whitman's Poetry // Walt Whitman: A Collection of Criticism / ed. by A. Golden. New York: McGraw-Hill Publ., 1974. P. 61-71.

Decker J. Henry Miller and narrative form: constructing the self, rejecting Modernity. New York; London: Routledge Publ.; Taylor \& Francis Inc. Publ., 2005. 182 p.

Gordon W. The Mind and Art of Henry Miller. Baton Rouge: Louisiana State Univ. Press, 1967. 232 p.

Ibargüen R. R. Narrative Detours: Henry Miller and the Rise of New Critical Modernism. PhD dissertation (Philosophy). Yale Univ., Faculty of the Graduate School of Yale University in Candidacy. New Haven, 1989. 379 p.

Rosenquist R. Modernism, the Market and the Institution of the New. Cambridge: Cambridge Univ. Press, 2009. $210 \mathrm{p}$.

Для цитирования: Аствацатуров А. А. Андрей Иванов и Генри Миллер: опыт сопоставительного анализа // Вестник СПбГУ. Серия 9. Филология. Востоковедение. Журналистика. 2016. Вып. 3. С. 101108. DOI: 10.21638/11701/spbu09.2016.312.

\section{References}

Astvatsaturov A. A. [Russian Kerouac in Estonia: Andrei Ivanov's Prose]. Kul'tura russkogo zarubezh'ia 1990-2010 [Culture of Russian Expatriate Community 1990-2010]. Proceedings of the international scientific conference. Ed. by A.L. Khlobystin. St. Petersburg, St. Petersburg State Univ., Faculty of Liberal Arts and Sciences Publ., 2013, pp. 145-149. (In Russian)

Astvatsaturov A. A. Sovremennaia literatura russkogo zarubezh'ia o Rossii: pisatel' Andrei Ivanov [Modern Literature about Russia of the Russian Expatriate Community: A Writer Andrei Ivanov]. Dinamika iazykovykh $i$ kul'turnykh protsessov v sovremennoi Rossii [Dynamics of Linguistic and Cultural Processes in Modern Russia]. Proceedings of the IV Congress "ROPRIaL", I Pedagogical forum "Russkii iazyk v sovre- 
mennoi shkole”. Sochi, 1-2 November, 2014. St. Petersburg, ROPRIaL Publ., 2014, vol.2, pp. 131-137. (In Russian)

Bavil'skii D. Ekaterinental'skii kvartet [Ekaterina Quartet]. Chastnyi korrespondent. 2014. 24 January. Available at: http://www.chaskor.ru/article/ekaterinentalskij_kvartet_32845 (accessed: 18.04.2015). (In Russian)

Belobrovtseva I. Pisatel'stvo kak postoiannaia stadiia zerkala. Andrei Ivanov [Writing Craft as a Constant Stage of the Mirror. Andrei Ivanov]. Voprosy literatury, 2014, no. 2, pp. 254-271. (In Russian)

Bloom H. The Anxiety of Influence. A Theory of Poetry. New York; Oxford, Oxford Univ. Press, 1997.

Coffman S.K. "Crossing Brooklin Ferry": a note on the Catalogue Technique in Whitman's Poetry. Walt Whitman: A Collection of Criticism. Ed. by A. Golden. New York, McGraw-Hill Publ., 1974, pp. 61-71.

Decker J. Henry Miller and narrative form: constructing the self, rejecting Modernity. New York; London, Routledge; Taylor \& Francis Inc. Publ., 2005. 182 p.

Deleuze G. Kritika i klinika [Critique and Clinic]. St. Petersburg, Machina Publ., 2002. 240 p. (In Russian)

Eliot T. S. Naznachenie poezii [Poetry Foundation]. Kiev, Airland Publ., 1996. 352 p. (In Russian)

Gordon W. The Mind and Art of Henry Miller. Baton Rouge, Louisiana State Univ. Press, 1967. 232 p.

Gur'ev M. Andrei Ivanov. Kharbinskie motyl'ki [Andrei Ivanov. Harbin Moths]. DELFI. 2014. 15 April. Available at: http://www.delfi.lv/showtime/news/culturepark/books/andrej-ivanov-harbinskiemotylki.d?id=44402845 (accessed: 18.04.2015). (In Russian)

Ibargüen R.R. Narrative Detours: Henry Miller and the Rise of New Critical Modernism. PhD dissertation (Philosophy). Yale Univ., New Haven, 1989. 379 p.

Ivanov A. Puteshestvie Khanumana na Lolland [Hanuman's Journey to Lolland]. Tallinn, Avenarius Publ., 2009. 332 p. (In Russian)

Ivanov A. Mne ne nuzhny kliuchi ot kvartiry v Parizhe [I don't need keys to the flat in Paris]. Novye oblaka, 2010, no. 1-2. Available at: http://tvz.org.ee/index.php?page=430 (accessed: 20.04.2015). (In Russian)

Ivanov A. Bizar [Bizarre]. Moscow, RIPOL klassik Publ., 2014. 352 p. (In Russian)

Kucherskaia M. Laureatom premii “NOS” stal pisatel' iz Tallina Andrei Ivanov [A writer from Tallinn Andrei Ivanov has become the Laureate of "NOS"]. Vedomosti. Issue Date: 27.01.2014. URL: http://www. vedomosti.ru/lifestyle/articles/2014/01/27/dikovinka (accessed: 18.04. 2015). (In Russian)

Levchenko I. Chitat' [To read]. Odnako. Available at: http://www.odnako.org/almanac/material/chitat-1 (accessed: 13.04.2015). (In Russian)

Miller H. Tropic of Capricorn. St. Petersburg, Azbuka Publ., 2000. 544 p. (In Russian)

Miller H. Tropic of Cancer. St. Petersburg, Azbuka Publ., 2000. 448 p. (In Russian)

Miller H. The Universe of Death. In: Miller, Henry. The Air-Conditioned Nightmare: esse, rasskazy [Essays, Stories]. Moscow, B. S. G.-PRESS; Pushkinskaia biblioteka Publ., 2001, pp. 343-368. (In Russian)

Miller H. The Colossus of Maroussi. St. Petersburg, Azbuka-klassika Publ., 2001. 320 p. (In Russian)

Miller H. Stand Still Like the Hummingbird: povesti, rasskazy, stat'i [Stories, Short Stories, Papers]. St. Petersburg, Azbuka, Azbuka-Attikus Publ., 2015. 320 p. (In Russian)

Podlubnova I. Budni “azulianta" [Days of "Azulyant"]. Ural, 2010, no. 12. Available at: http://uraljournal.ru/ work-2010-12-175 (accessed: 14.04.2015). (In Russian)

Rosenquist R. Modernism, the Market and the Institution of the New. Cambridge, Cambridge Univ. Press, 2009. $210 \mathrm{p}$.

Stepanov A.D. Andrei Ivanov. Puteshestvie Khanumana na Lolland [Andrei Ivanov. Hanuman's Journey to Lolland]. Prochtenie. 2010. 28 July. Available at: http://prochtenie.ru/reviews/24974 (accessed: 18.04.2015). (In Russian)

For citation: Astvatsaturov A. A. Andrei Ivanov and Henry Miller: Comparative Analysis. Vestnik SPbSU. Series 9. Philology. Asian Studies. Journalism, 2016, issue 3, pp. 101-108. DOI: 10.21638/11701/spbu09.2016.312.

Статья поступила в редакцию 19 мая 2015 г. Статья рекомендована в печать 28 марта 2016 г.

Контактная информация:

Аствацатуров Андрей Алексеевич - кандидат филологических наук, доцент; astvatsa@yandex.ru Astvatsaturov Andrey A. — PhD, Associate Professor; astvatsa@yandex.ru 